\title{
MONITORIA VIRTUAL: UM RECURSO METODOLÓGICO PARA AS AULAS PRÁTICAS DE HISTOLOGIA NO MODELO DE ENSINO REMOTO
}

\author{
VIRTUAL MONITORING: A METHODOLOGICAL RESOURCE FOR PRACTICAL HISTOLOGY CLASSES IN THE \\ REMOTE TEACHING MODEL
}

\section{MONITOREO VIRTUAL: UN RECURSO METODOLÓGICO PARA LAS CLASES DE HISTOLOGÍA PRÁCTICA EN EL MODELO DE ENSEÑANZA A DISTANCIA}

\author{
Karolayne Carvalho Silva ${ }^{1}$ \\ Giani Maria Cavalcante ${ }^{2}$
}

\begin{abstract}
${ }^{1}$ Graduanda em Enfermagem do Centro Universitário Maurício de Nassau, Caruaru, Pernambuco, Brasil.; 2 Doutorado em Biotecnologia pela UFRPE. Docente do Curso de Enfermagem do Centro Universitário Maurício de Nassau, Caruaru, Pernambuco, Brasil.

*Autor correspondente: gianimc@icloud.com
\end{abstract}

Recebido: 19/06/2021 | Aprovado: 16/08/2021 | Publicado: 19/08/2021

\begin{abstract}
Resumo: O distanciamento social imposto pela pandemia da Covid-19 obrigou o ensino presencial a interromper suas atividades, e migrá-las imediatamente para o sistema remoto de ensino, impondo as disciplinas com aulas práticas a uma adaptação imediatas dos seus conteúdos sem os espaços físicos e equipamentos que estas aulas requerem. O objetivo deste trabalho é apresentar o site Monitoria virtual de Histologia como um recurso metodológico digital em substituição as aulas práticas presenciais de Histologia durante o regime remoto de ensino. O presente trabalho é relato de experiência vivenciada no programa de monitoria da disciplina de Histologia. Para realizar a monitoria virtual, foi desenvolvido um site através de uma plataforma gratuita, que também é responsável pela hospedagem, intitulado como Monitoria virtual de Histologia. No site foram disponibilizados portfólios de imagens de cortes histológicos de diferentes tecidos de origem animal. De forma síncrona, a equipe de monitoria utilizava as imagens teciduais disponíveis para apresentar aos estudantes as características morfológicas e celulares de tecidos humanos. De forma assíncrona os estudantes utilizavam o site para confeccionar o portfólio digital. $87 \%$ dos estudantes que participaram da monitoria virtual acessaram o site durante as aulas síncronas, enquanto $92 \%$ dos estudantes acessaram o site em momentos assíncronos. Os novos cenários de ensino, impostos pela pandemia da Covid-19, impulsionou o desenvolvimento de um recurso metodológico que permitiu a apresentação dos conteúdos práticos da disciplina Histologia, através de um site possibilitando ao aluno acesso a estes conteúdos de forma síncrona e assíncrona.
\end{abstract}

Palavras-chave: Atividade pedagógica não presencial. Ensino de Ciências/Biologia. Prática Docente.

\begin{abstract}
The social distancing imposed by the Covid-19 pandemic forced classroom teaching to interrupt its activities, and immediately migrate them to the remote education system, imposing the disciplines with practical classes to an immediate adaptation of their contents without the physical spaces and equipment that these classes require. The objective of this work is to present the website Monitorial virtual de Histology as a digital methodological resource to replace the practical classes of Histology during the remote teaching regime. The present work is an account of the experience lived in the monitoring program of the discipline of Histology. To carry out the virtual monitoring, a website was developed through a free platform, which is also responsible for hosting, entitled Virtual Histology Monitoring. On the website, portfolios of images of histological sections of different tissues of animal origin were made available. Synchronously, the monitoring team used the available tissue images to present to the students the morphological and cellular characteristics of human tissues. Asynchronously, students used the website to create the digital portfolio. $87 \%$ of the students who participated in the virtual monitoring accessed the website during synchronous classes, while $92 \%$ of the students accessed the website in asynchronous moments. The new teaching scenarios, imposed by the Covid-19 pandemic, boosted the development of a methodological resource that allowed the presentation of the practical contents of the Histology discipline, through a website allowing the student to access these contents synchronously and asynchronously.
\end{abstract}

Keywords: Non-presential teaching activity. Science/Biology Teaching. Teaching practice.

Resumen: El distanciamiento social impuesto por la pandemia del Covid-19 obligó a la docencia en el aula a interrumpir sus actividades, e inmediatamente migrarlas al sistema educativo remoto, imponiendo las disciplinas con clases prácticas a una adaptación inmediata de sus contenidos sin los espacios físicos y equipamientos que estas clases exigir. El objetivo de este trabajo es presentar el sitio web Monitoria virtual de Histología como un recurso metodológico digital que sustituya a las clases prácticas de Histología durante el régimen de enseñanza a distancia. El presente trabajo es un relato de la experiencia vivida en el programa de seguimiento de la disciplina de Histología. Se desarrolló un sitio web a través de una plataforma gratuita denominado Monitorización Histológica Virtual. En el sitio web se pusieron a disposición portafolios de imágenes de cortes histológicos de diferentes tejidos de origen animal. Sincrónicamente, el equipo de seguimiento utilizó las imágenes de tejido para presentar a los estudiantes las características morfológicas y celulares de los tejidos humanos. De forma asincrónica, los estudiantes utilizaron para crear el portafolio digital. El 87\% de los estudiantes accedieron al sitio web durante las clases sincrónicas, mientras que el $92 \%$ de los estudiantes accedieron al sitio web en 
momentos asincrónicos. Los nuevos escenarios didácticos, impuestos por la pandemia del Covid-19, impulsaron el desarrollo de un recurso metodológico que permitió la presentación de los contenidos prácticos de la disciplina Histología, a través de un sitio web que permite al alumno acceder a estos contenidos de forma sincrónica y asincrónica.

Palabras-clave: Actividad docente no presencial. Enseñanza de Ciencias/Biología. Práctica docente.

\section{INTRODUÇÃO}

Segundo o Decreto no 9.235/2017 do Ministério da Educação, as universidades caracterizam-se pela inseparabilidade das atividades de ensino, pesquisa e extensão (Brasil, 2017). Nesse sentindo, a monitoria configura-se como uma categoria de ensino e aprendizagem que favorece de maneira integrada a inclusão do aluno nas atividades supracitadas (Santos, 2021).

A realização da monitoria permite que o discente-monitor seja inserido no processo ensinoaprendizagem e passe a colaborar com a aprendizagem de seus colegas, de modo que, ao mesmo tempo em que ensina, aprende; sendo também considerando um agente capaz de intensificar a relação professor-alunoinstituição o que possibilita a troca de saberes com os docentes, bem como com os discentes monitorados (Natário \& Santos, 2010; Silva et al., 2021).

A disciplina de Histologia, por sua vez, é parte integrante da grade curricular de uma gama de cursos de graduação em saúde. Esta disciplina estuda todos os tecidos presentes no corpo humano, bem como eles se organizam para formação de órgãos e sistemas altamente complexos (Santos \& Oliveira, 2020). Desta forma, a monitoria em uma disciplina que é fundamental para alicerçar as bases do conhecimento e promover habilidades e competências, para a formação profissional, acerca de base moleculares e celulares dos processos normais, da estrutura e função dos tecidos, órgãos, sistemas e aparelhos, tem o objetivo de aprimorar o aprendizado e facilitar a assimilação dos conteúdos através de diferentes metodologias de ensino (Boeira et al., 2020; Lanza et al., 2021).

No entanto, em virtude da pandemia causada pelo novo coronavírus (vírus SARS-CoV-2), alguns protocolos de isolamento social foram adotados, dentre eles a suspensão e substituição das aulas presenciais pelo sistema remoto de ensino e aprendizado, pelo tempo que durar a pandemia (Brasil, 2020). Nesse viés, as atividades atribuídas à monitoria também tiveram que ser adaptadas ao uso de tecnologias da informação, visando diminuir as lacunas, como ausência de acesso a aulas práticas presenciais, no aprendizado da disciplina objeto da monitoria (Guedes, Coronel \& Piranda, 2020).

Ao considerar a necessidade de integrar os conteúdos teóricos e práticos propostos pela disciplina de Histologia, a implantação do ensino remoto em virtude do distanciamento social no contexto da pandemia da Covid-19, impossibilitou o estudante a participação em aulas práticas presenciais, limitando estes aos conteúdos teóricos, sendo necessário o desenvolvimento e/ou utilização de recursos metodológicos que aproximem estes estudantes das habilidades práticas, que são necessárias para entender e assimilar, microscopicamente, a complexidade do funcionamento do corpo humano e de seus sistemas atuando de forma agregada e codependentes (Gonçalves et al., 2020; Ratis et al., 2021). 
Deste modo, o objetivo deste trabalho é apresentar o site Monitoria virtual de Histologia como um recurso metodológico digital em substituição as aulas práticas de Histologia durante o regime remoto de ensino.

\section{MATERIAL E MÉTODOS}

O presente trabalho é relato de experiência vivenciada no programa de monitoria da disciplina de Histologia, no período de março de 2020 a março de 2021, aplicada em modalidade de ensino não presencial em decorrência da pandemia da Covid-19, em uma Faculdade privada situada na cidade de Caruaru-PE, a partir da experiência relatada por Cavalcante et al. (2020). O programa tem duração de seis meses, podendo ser prorrogado por igual período, no qual os discentes são selecionados, via processo seletivo publicado em edital.

Os indivíduos que vivenciaram esta experiência foram estudantes dos cursos de Enfermagem, Farmácia, Fisioterapia e Nutrição, regulamente matriculados na disciplina de Histologia. Para possibilitar o acesso destes estudantes aos conteúdos práticos da disciplina em modalidade de ensino não presencial, foi criado um site para ser utilizado como recurso metodológico em substituição as aulas práticas presenciais.

Para desenvolver o site, a equipe de monitoria, utilizou a plataforma gratuita $W i x^{\circledR}$ a qual também serviu de hospedagem. O site recebeu o nome de "Monitoria virtual de Histologia", cujo acesso é feito através do endereço eletrônico (https://gimariantee.wixsite.com/monitoriavirtual).

O layout seguiu o padrão sugerido pela plataforma e ao mesmo foram adicionadas imagens captadas a partir de fotografia digital feita diretamente de lâminas histológicas em microscópio óptico. As lâminas utilizadas para captar as imagens compõem o acervo de laminários da instituição de ensino, as quais são utilizadas pelos estudantes em aulas práticas presenciais, através das quais é possível visualizar os cortes histológicos e suas características morfológicas e celulares. Com as imagens captadas foram construídos os portfólios digitais contendo diferentes estruturas teciduais que incluem: tecidos epiteliais, conjuntivos, cartilaginosos, ósseos e musculares. Além das imagens, para compor o site, foram confeccionados resumos com ênfase em características morfológicas e celulares pertinentes aos cortes histológicos disponíveis no site, e perguntas para compor o acervo de quiz. Toda construção e administração do site ficou a cargo da equipe de discentesmonitores.

De forma síncrona, a equipe de monitoria utilizava as imagens teciduais disponíveis no site para apresentar aos estudantes as características morfológicas e celulares de tecidos epiteliais, conjuntivos, cartilaginosos, ósseos e musculares. De forma assíncrona os estudantes utilizavam o site para confeccionar o portfólio digital utilizando fotografias de desenhos feitos a mão pelo próprio estudante, a ser enviado posteriormente através de e-mail, para equipe de monitoria como atividade de aula prática. 


\section{RESULTADOS E DISCUSSÃO}

De acordo com Amaral \& Polydoro. (2020), situações de crises demandam soluções criativas e inovadoras. Diante do cenário da pandemia da covid-19, o ensino remoto adotado pelas escolas e universidades, em decorrência da necessidade de um distanciamento social, possibilitou a continuidade das atividades acadêmicas através de interações síncronas e assíncronas, de modo que a transposição das aulas presenciais para o ambiente digital, não interrompesse as atividades acadêmicas e disciplinares dos estudantes.

A Histologia é uma disciplina ofertada nos períodos iniciais dos cursos de Saúde e Ciências Biológicas, que contempla a organização tecidual dos diferentes tipos de células e sua função na estrutura e constituição dos órgãos, sendo uma disciplina essencialmente de conteúdo descritivo e morfológico, cujos conteúdos abordados em aulas práticas e teóricas, tornam-se bases para o entendimento da anatomia, fisiologia e patologia (Cavalcante, Fonseca \& Costa, 2020; Araujo, Tetassicca \& Oliveira, 2021).

O site intitulado Monitoria virtual de Histologia (Figura 1), foi desenvolvido para ser utilizado como um recurso metodológico pela equipe de monitoria em substituição as aulas práticas presenciais.

Figura 1 - Site Monitoria Virtual de Histologia, desenvolvido pela equipe de monitoria da disciplina Histologia de uma faculdade privada situada em uma cidade do interior de Pernambuco-PE.

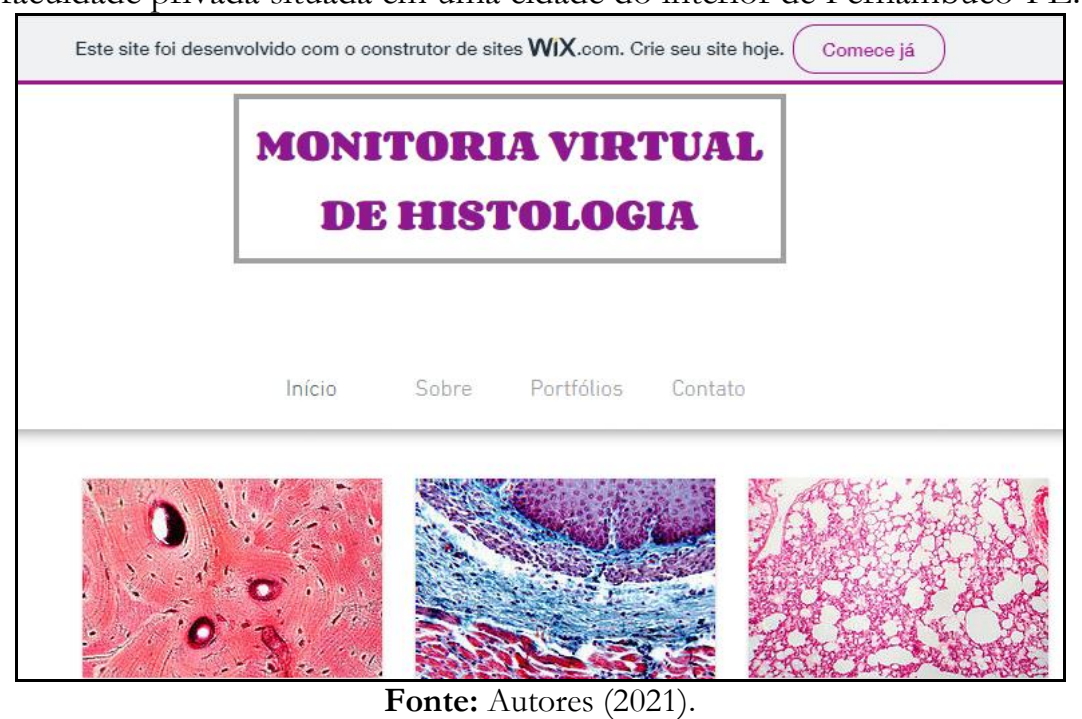

Desempenhar as atividades de monitoria, permite ao discente, habilidades, tanto intelectuais quanto sociais, além de ter uma ferramenta de iniciação à docência, uma vez que o monitor auxilia o professor no ensino de uma matéria, em geral na aplicação de exercícios, na elucidação de dúvidas, supervisão de atividades, entre outros (Braun \& Melo, 2020; Santos, 2021). No contexto da monitoria virtual, o site produzido tornou-se um recurso metodológico, onde através dele a equipe de monitoria passou ter disponível um portfólio de imagens com estruturas teciduais pertinentes aos tecidos epiteliais simples, estratificados e especiais; tecidos conjuntivos propriamente ditos e especiais, tecidos cartilaginosos, ósseos e musculares (Figura 2), auxiliando na integração dos conteúdos práticos aos conteúdos teóricos até o restabelecimento das atividades presenciais, além de servir como ferramenta para confecção de portfólio digital pelo estudante. 
Figura 2 - Portfólio de imagem de lâminas histológicas disponível no site Monitoria Virtual de Histologia, desenvolvido pela equipe de monitoria da disciplina Histologia de uma faculdade privada situada em uma cidade do interior de Pernambuco-PE.

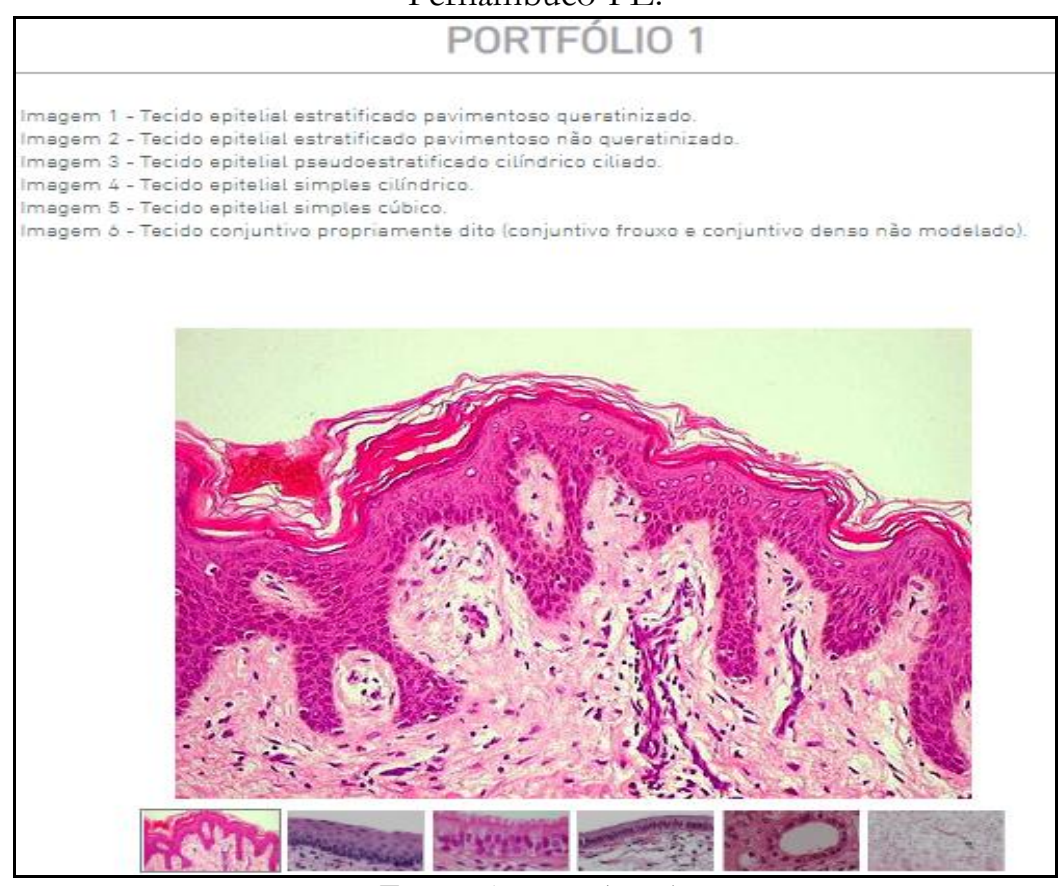

Fonte: Autores (2021).

De acordo com Silva \& Belo (2012), a prática de monitoria é de extrema relevância uma vez que o seu exercício se apresenta como um subsídio necessário à prática docente, permitindo ao aluno-monitor complementar seus conhecimentos, adquirir habilidades técnicas com o manuseio de materiais; a oportunidade de obter um contato mais próximo com a docência; a possibilidade de rever os conteúdos anteriormente aprendidos e de relacionar-se com outros estudantes. Na monitoria virtual de Histologia, os discentes monitores tiveram a oportunidade de experienciar o ensino remoto síncrono e assíncrono, usando a tecnologia da informação como ferramenta de ensino-aprendizagem, e principalmente, como recurso de continuidade de aprendizado, mesmo diante as suspensões de atividades presenciais, em decorrência da pandemia da covid-19, permitindo ao discente-monitor manter contato com a turma através da disponibilização de textos didáticostemáticos, quiz didático e resumos acadêmicos (Figura 3). 
Figura 3 - Disponibilização de textos didáticos-temáticos, quiz didático e resumos acadêmico no Site de Monitoria Virtual de Histologia, desenvolvido pela equipe de monitoria da disciplina Histologia de uma faculdade privada situada em uma cidade do interior de Pernambuco-PE.

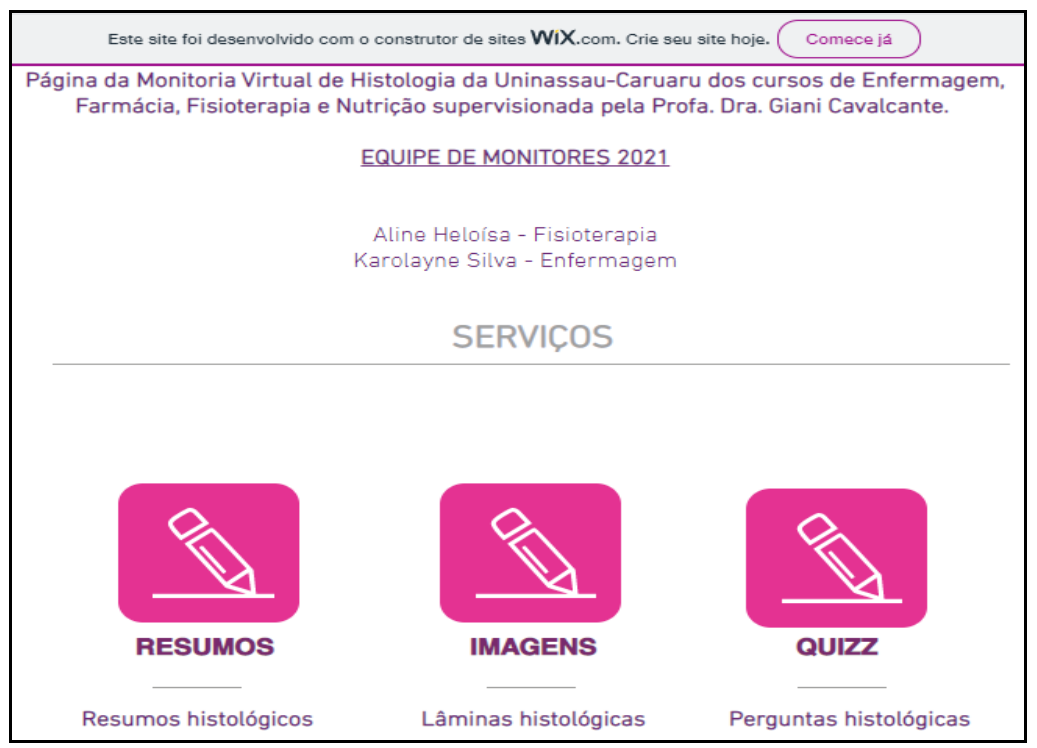

Fonte: Autores (2021).

Para Mesquita et al. (2019), a monitoria permite ampliar a visão em relação ao aluno, pois auxiliá-los na busca pelo conhecimento e usar ferramentas para associar a teoria à prática estimula na contribuição do ensino. Para a equipe de monitoria, o desenvolvimento de um site para ser utilizado como recurso de aulas práticas não presenciais de Histologia, foi uma experiência desafiadora, mas que favoreceu a comunicação e a interação entre a equipe de monitoria e os estudantes, e viabilizou o comprimento das atividades de monitoria acadêmica, estabelecidas no edital de seleção para monitoria, mesmo com a ausência de atividades presenciais em laboratórios e sala de aula.

As atividades realizadas pela equipe de monitora através do site Monitoria virtual de Histologia foi considerada satisfatória, uma vez que $87 \%$ dos estudantes envolvidos acessaram o site, este percentual foi registrado quando realizada as atividades síncronas através de frequência de participação na monitoria. Um total de $76 \%$ dos estudantes respondeu as questões propostas no quis e $71 \%$ baixaram os resumos disponibilizados no site. As atividades assíncronas proposta pela equipe de monitoria, foram realizadas por $92 \%$ dos estudantes envolvidos. As atividades assíncronas envolveram a confecção de portfólio digital utilizando fotografias de desenhos feitos a mão pelo próprio estudante (Figura 4), a partir do acesso e visualização dos cortes histológicos disponibilizados no site, e entregue a equipe de monitoria em documentos no formato do programa Microsoft Power Point ${ }^{\circledR}$, que é utilizada para criação/edição e exibição de apresentações gráficas. 
Figura 4 - Portfólio digital de imagens histológicas em Microsoft Power Point ${ }^{\circledR}$, desenvolvido pelos estudantes de uma faculdade privada situada em uma cidade do interior de Pernambuco-PE durante atividades assíncronas realizadas a parit do Site de Monitoria Virtual de Histologia.
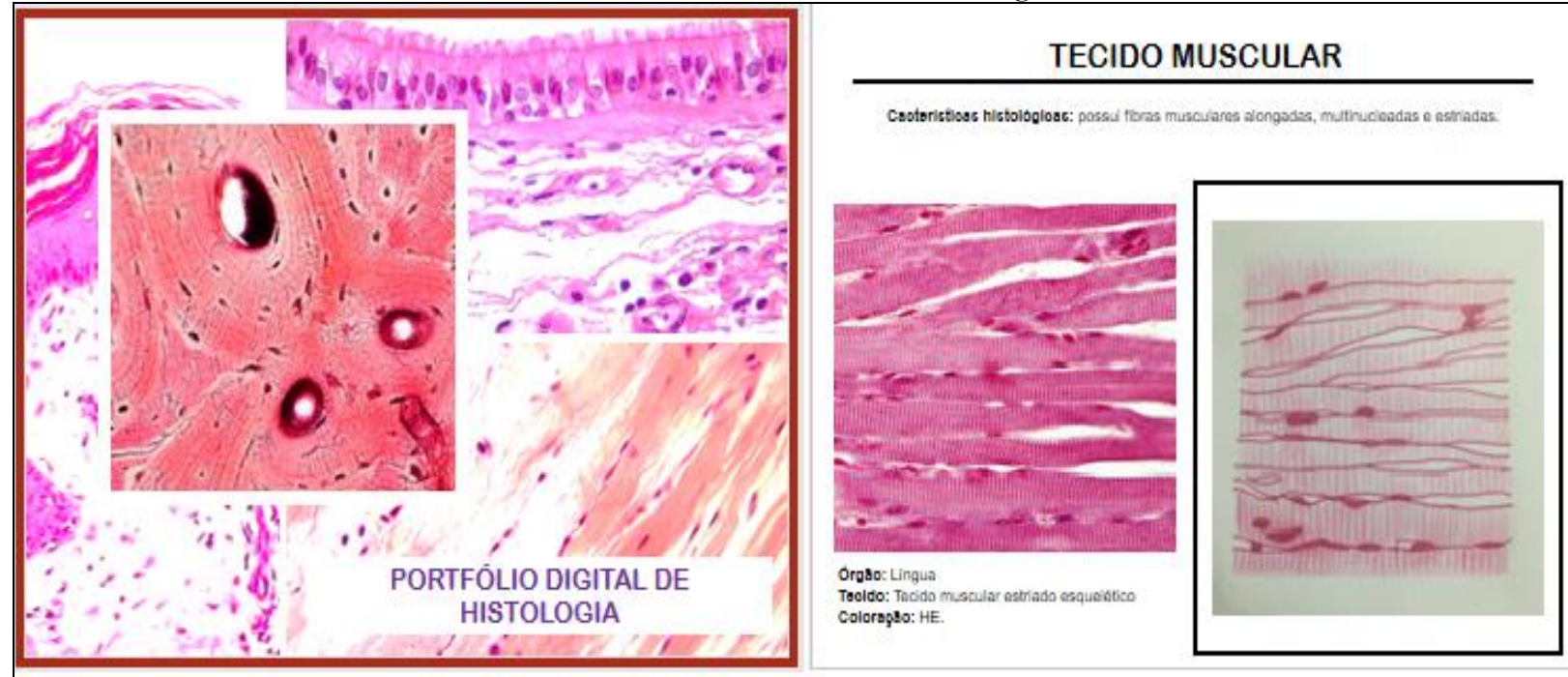

Fonte: Autores (2021)

Segundo Leite, Nascimento e Souza (2021), é preciso pensar no processo de ensino aprendizagem de forma em construir saberes baseados na realidade e na problematização em que docentes e estudantes participam conjuntamente e de forma efetiva do processo de ensino-aprendizagem, desta forma, a experiência vivenciada na monitoria virtual de Histologia, exemplifica a importância de adotar formas alternativas de comunicação entre monitores e alunos, e sobretudo viabilizar o acesso aos conteúdos práticos, mesmo em atividades não presenciais. Além disso, a monitoria remota de Histologia, permitiu ao aluno o auxílio do monitor, além de oferecer mais um recurso que lhe oportunizou realizar esclarecimento de dúvidas quanto ao conteúdo programático da disciplina e fazer a interação teórica e prática dos conteúdos de Histologia. Esta experiência mostra ser possível a expansão da ideia implantada na disciplina Histologia para outras disciplinas dos cursos participantes.

\section{CONCLUSÃO}

O atual cenário mundial que afetou diretamente o convívio social, incluindo as escolas e universidades, desafiou e impulsionou a busca por metodologias e recursos metodológicos que viabilizassem a ausência de aulas teóricas e práticas de modo presencial. No que tange as aulas práticas de Histologia, a criação de um site, desenvolvido por uma equipe de monitoria da disciplina, cujo conteúdo é formado por imagens de cortes histológicos oriundos do acervo laminário utilizados nas aulas presenciais, permitiu que os estudantes dos cursos de Enfermagem, Farmácia, Fisioterapia e Nutrição fossem apresentados as características morfológicas e celulares de diferentes tecidos corpóreos, através de uma plataforma digital com sessões de monitorias de forma síncrona e assíncrona, viabilizando a integração com os conteúdos teóricos apresentados pelo professor da disciplina, além de permitir a continuidade das atividades do discente-monitor, através de novas estratégias de ensino. 


\section{REFERÊNCIAS}

Amaral, E., Polydoro, S. (2020). Os desafios da mudança para o ensino remoto emergencial na graduação na UNICAMP-Brasil. Linha Mestra, 41(1), 52-62.

Araújo, T. M., Testasicca, M. C. S., Oliveira, A. R. (2021). Proposição de uma sequência didática complementar ao livro didático para o ensino de histologia animal no ensino médio. Experiências em Ensino de Ciências, 16(1), 159-185.

Boeira, S., Gomes, M. G. de Altvater, E. E. T., Jesse, C. R. (2020). Importância da monitoria em histologia, citologia e embriologia: contribuição ao ensino-aprendizagem. Abstract retrieved from https://periodicos.unipampa.edu.br/index.php/SIEPE/article/view/65036. Acesso em: 16 jun. 2021.

Brasil. Decreto $n^{\circ}$ 9.235, de 15 de dez̧embro de 2017. Dispõe sobre o exercício das funções de regulação, supervisão e avaliação das instituições de educação superior e dos cursos superiores de graduação e de pós-graduação no sistema federal de ensino. Brasília, DF: Presidência da República do Brasil.

Brasil. Portaria $n^{\circ} 345$, de 19 de março de 2020. Dispõe sobre a substituição das aulas presenciais por aulas em meios digitais enquanto durar a situação de pandemia do Novo Coronavírus - COVID-19. Brasília, DF: Presidência da República do Brasil.

Braun, M. S. A., Melo, S. S. (2020). A monitoria no processo de aprender a empreender. Revista Pemo, 2(2), 1-17. doi: $10.40149 /$ pemo.v2i2.3727.

Cavalcante, G. M., Fonseca, C.R.Q., Costa, N. B. (2020). Pandemia da covid-19 versus ensino remoto: adaptações nas aulas práticas de farmacologia para amenizar o impacto na aprendizagem. Covid-19: impactos da pandemia no Brasil e no mundo (pp.53-59). Rio de Janeiro, RJ: e-Publicar.

Gonçalves, R., Lara, M. V. S. de, Carpes, P. B. M., Vargas, L. da S. (2020). A importancia das atividades práticas nas disciplinas básicas para a formação em saúde. Abstract retrieved from

https://periodicos.unipampa.edu.br/index.php/SIEPE. Acesso em: 16 jun. 2021.

Guedes, M. B., Coronel, P. M. V., Piranda, E. M. (2020). Monitoria acadêmica de parasitologia no período de ensino remoto emergencial: relato de experiência. Abstract retrieved from

https://periodicos.ufms.br/index.php/IntegraEaD/article/view/11929. Acesso em: 16 jun. 2021.

Lanza C. C., Seabra, R. A. F. S., Coelho, A. C. P., Silva, Á., Martins, B. C. S., Sousa, G. C., Salvador, I. L. S., Carmo, L. R. \& Guimarães, P. R. (2021). Atividade de monitoria durante o Regime Letivo Remoto: relato de experiência no curso de medicina. Revista Eletrônica Acervo Saúde, 13(5), e7163. doi: 10.25248/reas.e7163.2021.

Leite, K. N. S., Souza, M. N. A., Nascimento, A. K., Souza, T. A. (2021). Utilização de metodologia ativa no ensino superior de saude: revisão integrativa. Arquivos de Ciencias da Saúde da UNIPAR, 25(2), 133-144.

Mesquita, G. N., Oliveira, J. G., Alves, A. L. N., Da Silva, L. M. S., Ribeiro, L. H., Silveira. T. (2019). Métodos de ensino integrados em monitoria de anatomia e Histologia: um relato de experiência. Revista Eletrônica Acervo Saúde, 30(1), e1370. doi:10.25248/reas.e1370.2019

Natario, E. G., Santos, A. A. A. (2010). Programa de monitores para o ensino superior. Estudos de Psicologia, 27(3), 355-364.

Ratis, L. R., Soareas, A. A., Ximenes, E. L. S., Pereira, M. G. A., Paula, M. V. O PROGRAMA RESIDÊNCIA PEDAGÓGICA EM PERÍODO DE PANDEMIA COVID-19: relatos de professores de Biologia em formação inicial. Journal of Education Science and Health, 1(3), 1-12. Doi: https://doi.org/10.52832/jesh.v1i3.26. 
Santos, L. C., Oliveira, C. L. C. (2020). O jogo digital quiz dos tecidos, as contribuições da monitoria para o ensino de histologia e para a formação acadêmica do monitor. Periódicos horizontes - USF, 38(1), 797-781. doi.org/10.24933/horizontes.v38i1.797.

Santos, M. M. (2021). Monitoria acadêmica presencial de citologia, histologia e embriologia e vídeo-aulas no youtube: relato de experiência. Revista Interfaces, 9(1), 993-997. doi: 10.16891/2317-434X.v9.e1.a2021.

Santos, E. A. V. (2021). Contribuições do programa de monitoria para a formaçõa acadêmica e docente do monitor licenciado em ciências biológicas. Educ. Ci. e Saúde, v. 8, n. 1, p. 236-255.

Silva, A. K. A. da, Ferreira, M. L. S., Oliveira, M. J. S., Silva, J. P. X., Machado, L. D. S., Xavier, S. P. L. (2021). Contribuições da monitoria acadêmica para a formação em enfermagem: revisão integrativa. Revista Enfermagem Atual in Derme, 95(33), 1-10. doi: 10.31011/reaid-2021-v.95-n.33-art.945.

Silva, R. N., Belo, M. L. M. (2012). Experiências e reflexões de monitoria: contribuição ao ensino-aprendizagem. Scientia Plena, 8(7), 1-6. 